\title{
EXTRACCIÓN Y CARACTERIZACIÓN DEL ALMIDON DE PAPA (Solanum tuberosum) VARIEDAD LEONA BLANCA
}

\section{EXTRACTION AND CHARACTERIZATION OF POTATO (Solanum tuberosum) STARCH LEONA BLANCA VARIETY}

\author{
Adriana Fernanda Vera Bravo ${ }^{1}$ \\ Manuel Antonio Chavarría Chavarría
}

(Recibido/received: 20-junio-2020; aceptado/accepted: 31-agosto-2020)

RESUMEN: La presente investigación tuvo como finalidad la extracción y caracterización de almidón de papa variedad Leona Blanca, para evaluar la posibilidad de su uso como ingrediente en la industria alimentaria. La variedad de tubérculo utilizado presentó forma oblonga, color de la pulpa blanca, de tamaño mediano y buena textura. El proceso de extracción del almidón se llevó a cabo mediante vía húmeda y por sedimentación natural, se caracterizó fisicoquímicamente presentando los siguientes valores: Humedad $12.660 \%$, Cenizas $0.853 \%$, Grasa $0.120 \%$, Fibra $0.140 \%$, Proteína $0.350 \%$, Carbohidratos $85.87 \%$, pH 6.34, Acidez 0.0027 meq de ácido láctico/g almidón. Los resultados obtenidos demuestran que su composición está dentro y no muy alejados de los rangos de comparación.

PALABRAS CLAVES: tubérculo; polisacárido; análisis fisicoquímicos

ABSTRAT: The purpose of this research was the extraction and characterization of potato starch variety Leona Blanca, to evaluate the possibility of its use as an ingredient in the food industry. The variety of tuber used presented oblong shape, white pulp color, medium size and good texture. The starch extraction process was carried out by means of a wet route and by natural sedimentation, it was characterized physicochemically presenting the following values: Humidity $12.660 \%$, Ash $0.853 \%$, Fat $0.120 \%$, Fiber $0.140 \%$, Protein $0.350 \%$, Carbohydrates $85.87 \%$, pH 6.34, Acidity 0.0027 meq lactic acid / g starch. The results obtained show that its composition is within and not far from the comparison ranges and that this type of starch can be included in food systems as a thickening agent, dusting agent, stabilizer, gelling agent, in the preparation of edible coatings and other industrial applications

KEY WORD: tuber; polysaccharide; physicochemical analysis

\footnotetext{
1 Maestrante de Agroindustria, Escuela Superior Politécnica Agropecuaria de Manabí "Manuel Félix López" Campus Politécnico El Limón, Km. 2.7 Vía calceta-El Morro- El Limón, sector La Pastora, Carrera de ingeniería en agroindustria, Calceta-Manabí-Ecuador; C.P.: 130250, adrianavera@espam.edu.ec, https://orcid.org/0000-00024942-6446.

${ }^{2}$ Magister en Agroindustria, Graduado en la Escuela Superior Politécnica Agropecuaria de Manabi "Manuel Félix López".
} 


\section{INTRODUCCIÓN}

En Ecuador se cultiva una gran diversidad de alimentos, entre ellos los tubérculos, los cuales gracias a su bajo costo y elevado valor nutritivo constituyen una de las principales fuentes de alimentación en los ecuatorianos (Loza, 2019). Sin embargo, según El Comercio (2019) en el país se pierden alrededor de 46000 toneladas al año de raíces y tubérculos, lo que es de gran preocupación para el campo agroindustrial ya que factores limitantes como las malas prácticas pos-cosecha, el alto contenido de humedad y activo metabolismo de estos alimentos, y el desconocimiento de los productores para la elaboración de nuevos productos, ha con llevado a la poca consideración de esta materia prima desde el punto de vista de la alimentación y la nutrición (Palomino, Molina, y Pérez, 2010).

Uno de los mayores componentes de las raíces y tubérculos es el almidón, el cual constituye la mayor fuente energética de las plantas. El almidón es una materia prima con un amplio campo de aplicaciones que van desde la impartición de textura y consistencia en alimentos hasta la manufactura de papel, adhesivos y empaques biodegradables. Debido a que el almidón es el polisacárido más utilizado como ingrediente funcional (espesante, estabilizante y gelificante) en la industria alimentaria, es necesario buscar nuevas fuentes de extracción.

El almidón presenta a nivel molecular partículas grandes y con fisuras, tiene brillo evidente, es un polvo blanco suave, inodoro y de sabor desagradable, el cual, puede ser usado para influir las propiedades físicas de muchos alimentos por los beneficios que ofrece (Polanco, 2014).

En la papa, el almidón constituye su principal fuente de almacenamiento de energía y su contenido varía según los cultivares y estado del crecimiento de la planta entre $15 \%$ y $20 \%$ de su peso y con un alto contenido de fósforo $(0.08 \%)$ en comparación con almidones de otras fuentes. La composición fisicoquímica tanto de la papa como la del almidón cambia según la variedad cultivada, la zona de crecimiento, la fertilización y el estado del ciclo de crecimiento de la planta. En el almidón de papa, la amilopectina se encuentra entre el $70 \%$ y $80 \%$ en peso, independiente del tamaño de los gránulos. Estas características hacen que el almidón de papa sea una fuente valiosa para la obtención de biopolímeros funcionales para la ciencia de los alimentos y de los materiales (Pardo, Castañeda, y Ortiz, 2013).

Debido a lo anterior, el almidón representa una excelente materia prima para la elaboración de productos novedosos y con buenas características, es por esto que la extracción y caracterización del almidón de papa constituyen una manera de preservar estos tubérculos a objeto de disminuir las pérdidas post-cosecha, aprovechando el potencial de éste en la industria a pequeña y gran escala y así satisfacer la demanda de materias primas, manteniendo una reserva y sistema de comercialización estables, que garanticen el suministro de estos cultivos en el ámbito nacional durante todo el año.

Por las razones antes expuestas, y tomando en cuenta que en Ecuador no se han realizado investigaciones específicas sobre almidones a partir de las variedades de papa procedente de la Región Andina, el objetivo del presente trabajo fue extraer y caracterizar el almidón de papa de la variedad Leona Blanca. 


\section{METODOLOGÍA}

La presente investigación fue de tipo documental-experimental, el método de recolección de datos fue de tipo cuantitativo porque se realizaron pruebas físicas y químicas del almidón extraído. Los análisis Físico Químicos se realizaron en el laboratorio de Bromatología de la carrera de Agroindustria de la Escuela Superior Politécnica Agropecuaria de Manabí "Manuel Félix López", ubicada en la provincia de Manabí, Bolívar-Calceta en el sitio El Limón. A una altitud de $15.5 \mathrm{msnm}$, temperatura promedio de $26^{\circ} \mathrm{C}$ y situada geográficamente entre las coordenadas 049'36.9" Latitud S y 8011'13.6" Longitud W (Google Maps).

\section{Materia prima:}

Para la obtención del almidón se utilizó papa (Solanum tuberosum) de la variedad Leona blanca, la cual fue adquirida en el mercado local de la ciudad de Calceta-Manabí-Ecuador. Esta variedad de tubérculo utilizado presentó forma oblonga, color de la pulpa blanca, de tamaño mediano y buena textura.

\section{Extracción del almidón:}

El almidón de papa de la variedad Leona Blanca, se extrajo según la metodología propuesta por Aristizábal y Sánchez (2007). Para el presente estudio se emplearon $8 \mathrm{~kg}$ de papas, de los cuales se descartaron las impurezas y tubérculos dañados. Los tubérculos en buen estado fueron lavados, pelados y cortados en finas rodajas, las cuales fueron trituradas en una licuadora marca OSTER Modelo BLSTMG-W00-013, 450W de potencia. Luego el producto obtenido se filtró con la ayuda de un lienzo, realizando varios lavados de la pulpa con agua destilada para retirar todo el almidón hasta que el líquido saliera claro. Se continuó con la sedimentación de los lavados durante 4 horas, se separó el agua presente y la pasta resultante se sometió a secado en estufa marca MEMMERT por 24 horas a $48^{\circ} \mathrm{C}$; finalmente se molió el almidón resultante en un molino manual marca CORONA y se almacenó en bolsas con cierre hermético de polipropileno calibre de 0,002 $\mathrm{m}$ en ambiente seco.

\section{Caracterización fisicoquímica del almidón de papa:}

El contenido porcentual de humedad del almidón se determinó mediante el método gravimétrico de secado por estufa donde se pesó en una balanza digital marca SARTORIUS $3 \mathrm{~g}$ de muestra en una caja petrix con tapa (previamente pesado después de tenerlo por 2 horas a $130^{\circ} \mathrm{C}$ ) y se sometió a secado en la estufa por 2 horas a $135^{\circ} \mathrm{C}$. Luego al retirar la muestra seca de la estufa, se tapó la caja petrix y se la dejó enfriar en el desecador durante 30 minutos para luego ser pesado y calcular el porcentaje de humedad mediante la siguiente fórmula:

$$
\% \text { Humedad }=\frac{\text { Peso de la Muestra }- \text { Peso de muestra despues de estufa }}{\text { Peso de la muestra }} * 100
$$

El contenido porcentual de cenizas se determinó según el método de calcinación seca utilizando una mufla marca FURNACE. Se pesó $3 \mathrm{~g}$ de muestra en el crisol (previamente colocado durante 2 horas en la mufla a $600^{\circ} \mathrm{C}$ y pesado) y se calcinó con ayuda del mechero de Bunsen dentro de la campana durante 25 minutos, posteriormente se llevó a la mufla por 2 horas a $600^{\circ} \mathrm{C}$ y así conseguir unas cenizas blancas o ligeramente grises y homogéneas. Se dejó enfriar en el desecador por 25 minutos, se tomó el peso y se realizó el cálculo con la siguiente fórmula: 


$$
\% \text { Cenizas }=\frac{\text { Peso de Muestra despues de mufla }}{\text { Peso de la muestra }} * 100
$$

El contenido porcentual de grasa se determinó por el método gravimétrico Soxhlet. Se pesó 3 gramos de muestra en un papel filtro, se selló la muestra y se introdujo en el balón previamente tarado al cual se le adicionó $150 \mathrm{~mL}$ de hexano y se procedió a la extracción en el equipo Soxhlet con una temperatura en la plancha de calentamiento de $75^{\circ} \mathrm{C}$ durante 4 horas. El residuo se llevó a estufa por 1 hora y a $105^{\circ} \mathrm{C}$, se enfrió en el desecador por 25 minutos, se pesó y se realizó el cálculo con la siguiente fórmula:

$$
\% \text { Grasa }=\frac{\text { Peso de Muestra despues de estufa }}{\text { Peso de la muestra }} * 100
$$

El contenido porcentual de proteína se determinó mediante el método Kjeldahl. Se pesó 3 gramos de muestra en papel filtro y se transfirió en forma de paquetito al balón, luego se agregó la pastilla Kjeldahl y $25 \mathrm{ml}$ de $\mathrm{H}_{2} \mathrm{SO}_{4}$ concentrado, se colocó el balón el reverbero del digestor para calentar hasta que carbonizara y, al entrar en ebullición y cuando se obtuvo un líquido claro, se mantuvo hirviendo durante 30 minutos. Luego se dejó enfriar para agregar $150 \mathrm{~mL}$ de agua destilada y dejar en reposo. Se agregó al balón 40 gramos de parafina, $80 \mathrm{~mL}$ de soda Kjeldahl y 7 granallas de Zinc y se sometió a destilación en el mismo equipo Kjeldahl, habiendo colocado al final del tubo de desprendimiento un Erlenmeyer con $50 \mathrm{ml} \mathrm{de}_{2} \mathrm{SO}_{4}$ al $0.1 \mathrm{~N}$ y 2 gotas de solución indicador rojo de metilo, por 20 minutos. El destilado obtenido se tituló con $\mathrm{NaOH} 0.1 \mathrm{~N}$ hasta obtener un viraje amarillo y se realizaron los cálculos con la siguiente fórmula:

$$
\% P=\frac{\left[\left(\text { Consumo de } \mathrm{H}_{2} \mathrm{SO}_{4} * \mathrm{~N}\right)-(\text { Consumo de } \mathrm{NaOH} * \mathrm{~N})\right] * 0.014 * F_{C}}{\text { Peso de la muestra }} * 100
$$

El contenido porcentual de fibra se determinó por el método Standard (AOAC 962.09). Se

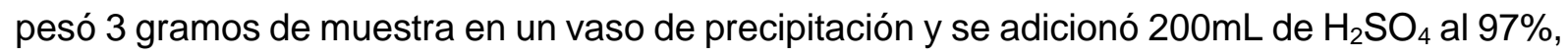
se colocó en el digestor de fibra para que hirviera durante 30 minutos, y se dejó enfriar hasta temperatura ambiente. Luego se filtró a través de una tela lino colocada en un embudo y se lavó el vaso de precipitación con agua destilada y se filtró el residuo. El residuo obtenido se colocó en otro vaso de precipitación, se le agregó $200 \mathrm{~mL}$ de $\mathrm{NaOH}$ al $0.1 \mathrm{~N}$, se colocó nuevamente en el digestor de fibra para que hirviera durante 30 minutos y luego se enfrió a temperatura ambiente. Posteriormente se filtró a través de la tela lino puesta en el embudo lavando el vaso de precipitación con agua destilada y alcohol. El residuo obtenido se transfirió al crisol para luego colocarlo en estufa por 2 horas a $130^{\circ} \mathrm{C}$, se enfrió en el desecador y se tomó el peso. Finalmente, el crisol y su contenido se colocaron en la mufla durante 30 minutos a $600^{\circ} \mathrm{C}$, la muestra se dejó enfriar luego en el desecador y se tomó el peso para realizar los cálculos respectivos mediante la siguiente fórmula:

$$
\% \text { Fibra }=\frac{\text { Peso de Muestra despues de estufa }- \text { Peso de Muestra despues de mufla }}{\text { Peso de la muestra }} * 100
$$

El valor de $\mathrm{pH}$ se lo realizó por el método potenciométrico. Se pesaron 10 gramos de almidón en un vaso de precipitación, se enrazó con agua destilada hasta $60 \mathrm{~mL}$, se le colocó una bala 
magnética dentro de la disolución y se sometió a agitación por 30 minutos a 300 rpm. Se retiró la bala magnética y se introdujo el potenciómetro para medir directamente el pH de la muestra El contenido de acidez se determinó por titulación. Se pesaron 5 gramos de muestra en un papel filtro y se dejó caer con cuidado dentro de una probeta, luego se le añadió $50 \mathrm{~mL}$ de alcohol neutro, se agitó con una varilla de vidrio y se dejó reposar por 24 horas. Transcurrido este tiempo se tomó una alícuota $(10 \mathrm{~mL})$ del líquido sobrenadante con una pipeta volumétrica, se pasó a una fiola y se le agregó 3 gotas de fenolftaleína donde se tituló con $\mathrm{NaOH}$ al $0.1 \mathrm{~N}$ hasta la aparición de un color rosado. Se anotó el consumo y se realizaron los cálculos mediante la siguiente fórmula:

$$
\%=\frac{\text { Consumo de NaOH } * N * \text { mlq.ác. }}{\text { Peso de la muestra }} * 100
$$

El porcentaje de carbohidratos se determinó por diferencia aplicando la siguiente fórmula:

$$
\%=100-\% H-\% C-\% G-\% P
$$

\section{RESULTADOS Y DISCUSIÓN}

Se caracterizó el almidón de papa variedad Leona blanca y los resultados de los análisis realizados se muestran en la tabla 1.

Tabla 1. Resultados de la caracterización físico química del almidón de papa

\begin{tabular}{lcc}
\hline \multicolumn{1}{c}{ Parámetro } & $\overline{\boldsymbol{X}}$ & D.E \\
\hline Humedad & $12.660 \%$ & 0,001 \\
\hline Cenizas & $0.853 \%$ & 0,001 \\
\hline Grasa & $0.120 \%$ & 0 \\
\hline Proteína & $0.350 \%$ & 0,001 \\
\hline Fibra & $0.140 \%$ & 0 \\
\hline Carbohidratos & $86.010 \%$ & 0,001 \\
\hline pH & 6.34 & 0,005 \\
\hline Acidez & 0.0027 meq de ác. Lác./g & $5 \times 10^{-05}$ \\
\hline
\end{tabular}

En el presente estudio, el contenido de humedad en el almidón de papa variedad Leona blanca fue de $12.66 \%$, este valor está dentro de los rangos reportados por Martínez, Málaga, Betalleluz, Ibarz y Velezmoro (2015) (14.15\% a 15.62\%) en almidones obtenidos de 7 variedades de papas nativas procedentes de Pampacorral. Así mismo, este valor está próximo al reportado por Rebaza (2019)(12.20\%) para el almidón de papa en la variedad Bretaña; sin embargo, tanto Loza (2019) como Alvis, Vélez, Villada y Rada-Mendoza (2008) reportan valores menores en el almidón de papa china y almidón de papa variedad ICA-Nariño respectivamente $(9.30 \%$ y $8.50 \%$ de humedad); Moorthy (2002) menciona que el contenido de humedad del almidón seco varía desde $6 \%$ hasta 16\%, dependiendo en el proceso que se utiliza para el secado del almidón y que mayores niveles de humedad pueden producir daños microbianos y su posterior deterioro de la calidad.

El contenido de cenizas para el almidón de papa variedad Leona blanca de $0.853 \%$ el cual es mayor a los reportados tanto por Alvis, Vélez, Villada y Rada-Mendoza (2008) (0.44\%) en almidón de papa variedad ICA-Nariño como por Rebaza (2019) (0.39\%) para el almidón de 
papa en la variedad Bretaña; Vargas, Martínez, y Velezmoro (2016) manifiestan que el contenido de cenizas presentes en los almidones representa la cantidad de minerales y sales remanentes que quedaron producto de la extracción y del contenido de minerales de la materia prima. El contenido de grasa en el almidón del presente estudio fue de $0.12 \%$ el cual es menor al reportado por Vargas, Martínez, y Velezmoro (2016) $(0.30 \%)$ en almidón de una variedad comercial de papa y al reportado por Alvis, Vélez, Villada y Rada-Mendoza (2008) $(0.35 \%)$ en almidón de papa variedad ICA-Nariño. Melian (2010) mantiene que el contenido de grasa puede influir sobre el comportamiento reológico de los almidones y en consecuencia disminuye la viscosidad de la pasta y la fuerza del gel. El contenido de proteína en el almidón de papa $(0.350 \%)$ está dentro de los rangos de valores reportados para almidones nativos en doce variedades de papa por Melian (2010) (0.12 - $0.59 \%$ ) así como los reportados por Vargas, Martínez, y Velezmoro (2016) (0.40\% y 0.54\%) en almidón de una variedad comercial de papa y los reportados por Acosta, Gomajoa, Benavides, Charfuelan, Valenzuela, (2018) $(0.341 \%$ y $0.753 \%)$ para almidones en cinco variedades de papa. Melian (2010) manifiesta que un alto contenido de proteína en el almidón, cambia sus propiedades fisicoquímicas influyendo en su viscosidad, además le confiere una capacidad a espumar. Peña (2017) afirma que un contenido de proteína en el almidón, como máximo de cinco por ciento, no tiene efecto significativo sobre las propiedades térmicas del almidón.

El contenido de fibra del almidón de papa fue de $0.14 \%$, mayor al valor reportado por Alvis et al. (2008) (0.05\%) en almidón de papa variedad ICA Nariño y al reportado por Herrera (2015) $(0.0093 \%)$ en un almidón de papa nativa; Sin embargo, se encuentra dentro del rango reportado por Izarra y Yantas (2012) (0.13\% a 0.19\%) en almidón de tres variedades de papa. El contenido de fibra en el almidón es deficiente; existen diferentes factores que afectan el contenido de fibra como es la fuente de obtención y el estado de madurez (a mayor madurez, mayor contenido de fibra) (Gutiérrez, 1980). Singh y Kaur (2009) mencionan que el almidón de papa es el de mayor pureza debido a la gran presencia de carbohidratos. Vargas, Martínez, y Velezmoro (2016) reportan valor de carbohidratos $98.80 \%$ en almidón de una variedad comercial de papa, así como Peña (2017) reporta valores para almidones de cinco variedades de papa entre $98.97 \%$ a $99.16 \%$. Sin embargo, para el presente estudio se obtuvo un valor menor $(85.87 \%)$ que se pudo deber al método de extracción del almidón; sin embargo, este valor está próximo al rango reportado por Díaz (2015) (88.09\% a 88.84 \%) en almidón de cuatro variedades de papa nativa.

El valor de pH en el almidón de papa fue de 6.34 el cual está dentro de los rangos reportados por Díaz (2015) (6.30 a 6.93) en almidón de cuatro variedades de papa nativa; Así mismo este valor está muy próximo al rango reportado por Izarra y Yantas (2012) (6.35 a 6.45) para almidones de tres variedades de papa en la región de Jauja. La diferencia se debe a que el $\mathrm{pH}$ de un almidón disminuye, cuando sucede una fermentación ácida donde el crecimiento de hongos libera amoniaco e incrementa el valor del pH. Aristizabal y Sánchez (2007) afirman que un almidón debe estar entre 6.0-6.5, así que el almidón de papa del presente estudio está dentro de estos límites. En cuanto a la acidez del almidón estudiado cuyo valor es de 0.0027 meq de ácido láctico/g almidón está dentro del rango expuesto por Aristizabal y Sánchez (2007), quien indica que un almidón nativo debe tener una acidez de 0.002 y 0.005 meq de ácido láctico/g de almidón; así mismo, está próximo al rango reportado por Díaz (2015) (de 0.0047 a 0.0053 ácido láctico/g de almidón) en almidón de cuatro variedades de papa nativa. 


\section{CONCLUSIONES}

El presente estudio de caracterización del almidón de papa representa un gran aporte para determinar sus usos específicos en relación a las características estudiadas dentro de la industria alimentaria; dando así un gran valor agregado para la comercialización de papas ecuatorianas.

En la caracterización del almidón de papa variedad Leona Blanca se comprobó que el contenido de humedad fue de $12.660 \%$ el cual se encuentra dentro de los rangos comparados, lo que nos indica estabilidad en el producto ya que un contenido superior de humedad puede ocasionar daño microbiano y deterioro en la calidad del polímero. Mientras que el contenido de ceniza fue de $0.853 \%$, valor mucho mayor a los de comparación, este incremento en la cantidad de cenizas está relacionado con un aumento en el contenido de minerales en el almidón de papa.

El contenido de grasa fue menor a los valores comparados, lo cual es un buen indicativo de calidad ya que la presencia de grasas en el almidón afecta a las propiedades funcionales, al evitar su unión con las moléculas de agua y causar rancidez durante el almacenamiento.

El contenido de proteínas en el almidón estuvo dentro de los rangos comparados estudiado, sin embargo, debería ser menor ya que un alto contenido de proteína en el almidón, cambia sus propiedades fisicoquímicas influyendo en su viscosidad, además le confiere una capacidad a espumar. La presencia de proteínas en el almidón pudo ser a causa de los diferentes lavados que sufrió durante su obtención, ya que el agua ayuda a arrastrar a las proteínas.

El contenido de fibras en el almidón es indicativo del estado de madurez de la materia prima por lo que, según el valor obtenido, la papa variedad tenía una mayor madurez en comparación con las variedades de los valores comparados.

En cuanto al contenido de carbohidratos, el valor obtenido fue menor a los rangos comparados lo cual indica una mínima baja en el grado de pureza del almidón de papa estudiado, ya que a mayor cantidad de carbohidratos mayor será el grado de pureza del mismo.

El valor de $\mathrm{pH}$ y acidez del almidón estudiado está acorde a los rangos de comparación y a los establecidos para un almidón de tubérculos

\section{BIBLIOGRAFÍA}

Acosta, J., Gomajoa, H., Benavides, Y., Charfuelan, A., Valenzuela, F. (2018). Evaluación del almidón de papa (Solanum tuberosum) en la obtención de bioplástico. Disponible en: http://dx.doi.org/10.21931/RB/CS/2018.01.01.2

Alvis, A., Vélez, C. A., Villada, H. S., \& Rada-Mendoza, M. (2008). Análisis físico-químico y morfológico de almidones de ñame, yuca y papa y determinación de la viscosidad de las pastas. Información tecnológica, 19(1), 19-28.

Aristizábal, J.; y Sánchez, T. 2007. Extracción de almidón de yuca. Guía técnica para producción y análisis de almidón de yuca. Roma, Italia: FAO. 7:49 - 57. 
Caicedo, N. B. M., \& Ibarra, A. A. R. (2017, August). Estado actual de los niveles de desperdicio de las cadenas de abastecimiento de alimentos. In Memorias de Congresos UTP (pp. 202-209).

Diaz Barrera, Y. (2015). Determinación de la spropiedades físicas, químicas, tecnofuncionales y la estabilidad en congelación/descongelación del almidón de cuatro variedades de solanum tuberosum ssp. andigenum (papa nativa). Tesis para optar el título profesional de ingeniero Agroindustrial. Universidad Nacional José María Arguedas. Perú

Gutiérrez Freire, V. H. (1980). Inventario y valor nutritivo de las principales especies forrajeras de la provincia de Carchi (tesis de grado). Escuela superior politécnica de Chimborazo, Ecuador

Herrera, M. E. T. (2015). Evaluación del almidón de papa como floculante para el tratamiento de aguas residuales domésticas. @ limentech, Ciencia y Tecnología Alimentaria, 13(2), 123-135.

Izarra, S., Davis, R., \& Yantas Huaynate, P. E. (2012). Evaluación de la calidad del almidón obtenido de tres variedades de papa (Solanum tuberosum) cultivadas en la provincia de Jauja. Tesis Para optar el Título Profesional de Ingeniero Agroindustrial. Tama - Perú

Loza, M. J. S. (2019). Extracción y uso de almidón de papa china (Colocasia Esculenta) en la elaboración de productos cárnicos emulsionados (Doctoral dissertation) UNIVERSIDAD DE CUENCA. Cuenca - Ecuador

Melian, D. 2010. Ensayo comparativo de dos metodologías de extracción de almidón de papa usando muestras de diez variedades nativas de Chile y dos variedades comerciales. Tesis para optar el grado de licenciado en Ciencia de Alimentos. Escuela de Ingeniería de los Alimentos. Universidad Austral de Chile. Valdivia, Chile.

Moorthy, S. N. (2002). Physicochemical and functional properties of tropical tuber starches: a review. Starch-Stärke, 54(12), 559-592.

Palomino, C., Molina, Y., \& Pérez, E. (2010). Atributos físicos y composición química de harinas y almidones de los tubérculos de Colocasia esculenta (L.) Schott y Xanthosoma sagittifolium (L.) Schott. Rev. Fac. Agron.(UCV), 36(2), 58-66.

Pardo, O. H., Castañeda, J. C., \& Ortiz, C. A. (2013). Caracterización estructural y térmica de almidones provenientes de diferentes variedades de papa. Acta Agronómica, 62(4), 289-295.

Peña Carrasco, E. F. (2017). Extracción y caracterización fisicoquímica y funcional de almidones de cinco variedades de papas nativas procedentes de llave (Puno). Tesis para optar el título de ingeniero en industrias alimentarias. Universidad Nacional Agraria La Molina. Lima-perú

Polanco, L. Z. (2014). Extracción y caracterización de almidón nativo de clones promisorios de papa criolla (Solanum tuberosum, Grupo Phureja). Revista Latinoamericana de la papa, 18(1), 1-24.

Rebaza C. M. G. (2019). Propiedades reológicas y texturales de geles de almidón de papa (Solanum tuberosum L.) entrecruzado, variedad Bretaña. Tesis para optar el título profesional de ingeniero agroindustrial. Universidad Nacional de Trujillo. Perú 
Singh, J.; Kaur, L. 2009. Advances in potato chemistry and technology. First Edition. Editorial Academic Press, Burlington, MA. USA. 508 pp.

Vargas, G., Martínez, P., \& Velezmoro, C. (2016). Propiedades funcionales de almidón de papa (Solanum tuberosum) y su modificación química por acetilación. Scientia Agropecuaria, 7(SPE), 223-230.

\section{SEMBLANZA DE AUTORES}
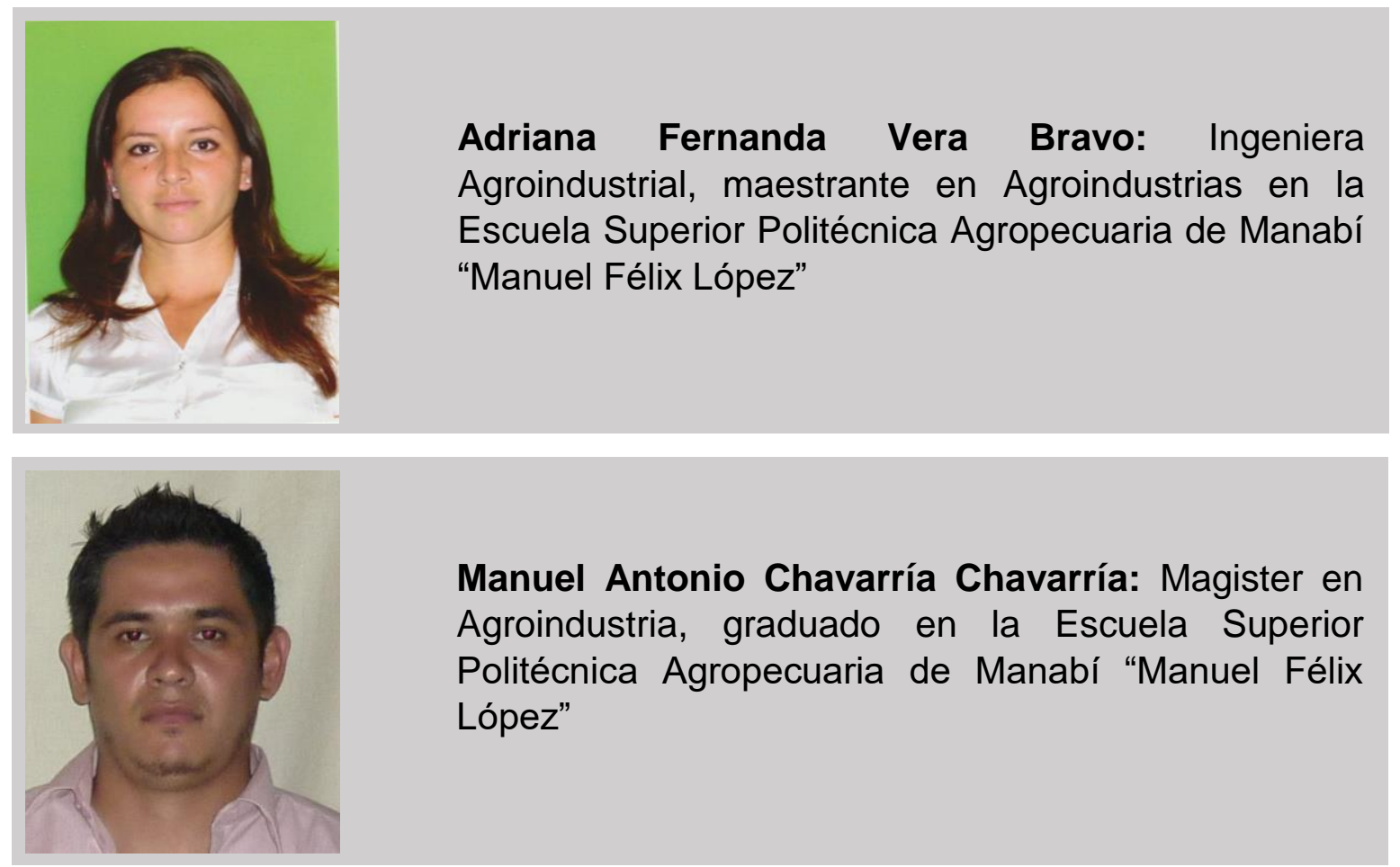